\title{
玄武岩柱状节理一一种自组织现象?
}

玄武岩柱状节理是发育于玄武岩中的一 种原生张性破裂构造, 它以形成两层粗细和 长短不同的玄武岩多边形 (以六边形为主) 柱 体为特征. 长期以来, 人们对它的成因一直 持传统的“冷却收缩说”观点 ${ }^{[1-3]} .1981$ 年, Kantha 从海洋物理学中的 “盐指作用” 得到 启发,提出了“双扩散对流说”, 并引人了“玄 武岩指”的新概念 10 .

Benard 对流是 Prigogine 所引用的典 型的自组织现象之一州. 鉴于玄武岩指与 Benard 对流格子在形态和形成因素上 都非 常相似, 因此我们认为, 玄武岩指实为喷出的 玄武岩浆熔体由于其冷面和内部在温度和 化学成分上的差异所形成的一种耗散结 构, 而玄武岩柱状节理则是这种耗散结构经岩将 冷凝固结成岩而得以保留的产物. 这一结论 从非平衡态热力学的角度支持了 “双扩散对 流说”。

图 1 示意玄武岩指的形成机制。 $a a^{\prime}$ 为岩 流顶部冷凝面即熔岩流与大气之间的界面, $b b^{\prime}$ 为岩流底部冷凝面即熔岩流与下伏基岩 之间的界面, $h$ 表示熔岩流的厚度, 其中 $a a^{\prime}$ 、 $b b^{\prime} \gg h . T_{1} 、 T_{2}$ 分别表示底部冷凝面和顶 部冷凝面的温度, $T_{0}$ 表示岩流内部的最高温 度, 其中 $T_{0}>T_{1}>T_{2}, \Delta T_{1}=T_{0}-T_{1}$, $\Delta T_{2}-T_{0}-T_{2}\left(\Delta T_{1}<\Delta T_{2}\right)$. 当 $\Delta T_{1} 、 \Delta T_{2}$ $<\Delta T_{\text {。 }}$ (某一间值) 时, 熔体处于平衡状态. 但当 $\Delta T_{1} 、 \Delta T_{2}>\Delta T_{6}$ 时, 熔体的静止热传 导状态就会被突然打破, 代之的是双扩散对 流状态(图 1)即形成两层六方对流柱指。由 于 $\Delta T_{1}<\Delta T_{2}$, 所以下层柱指比上层柱指粗 而短.

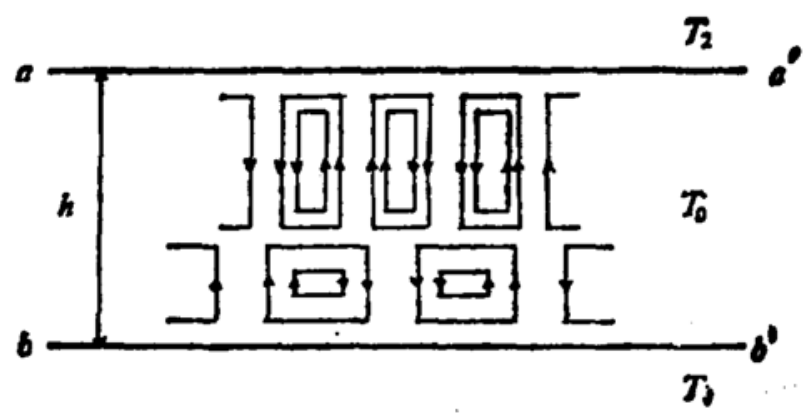

图 1 玄武岩指的形成机制

此外，玄武岩指只有在适当的岩浆成分 (粘度)、古气候条件(低于一定的温度)、古地 形条件(地形较为平坦)和蛞岩流厚度 (达到 一定的大小)的情况下方可产生, 从而玄武岩 柱状节理才能形成。

致谢：在本文的研究工作中，周新民教授曾多 次给予鼓䣦和指导,作者谨此致谢 .

\section{考文 姑}

[:] Iddings, J. P., Amer. Journ. Sci., 31(1886), 3: $321-331$.

[2] Beard, C. H., Bull. Geol. Soc. Amer., 70 (1959), 3: 379-381.

[3] Ryan, M. P., Sammis, C. G., Geol. Soc. Amer. Bull., 89(1978), 9: 1295-1308.

[4] Kantha, L. H., Geol. Mag.,118(1981), 3:251264.

[5] Reichl, L. E., A Modern Course in Statistical Physics, University of Texas Press, Austin, 1980, 644-654.

徐洪武

（南京化工学院硬酸盐工程系,南京 210009）

徐意芳

(笑国恶普金斯大学地球和行星科学系)

邻海波

（南京大学地球科学系,南京 210008） 